\title{
Application of Analytic Hierarchical Process Method for Video Game Genre Selection
}

\author{
Elaachak Lotfi \\ Computer science, systems \\ and telecommunication \\ Laboratory (LiST) \\ Faculty of Sciences and \\ Technologies \\ Abdelmalek Essaadi University \\ Tangier, Morocco
}

\author{
Belahbib Amine \\ Computer science, systems \\ and telecommunication \\ Laboratory (LiST) \\ Faculty of Sciences and \\ Technologies \\ Abdelmalek Essaadi University \\ Tangier, Morocco
}

\author{
Bouhorma Mohammed \\ Computer science, systems \\ and telecommunication \\ Laboratory (LiST) \\ Faculty of Sciences and \\ Technologies \\ Abdelmalek Essaadi University \\ Tangier, Morocco
}

\begin{abstract}
The game genre is an important feature for organizing, accessing and developing video games; however the choice of the genre during the process of video games making requires expertise and thorough study which can sometimes lead to unexpected issues due to the bad choice that can affect the final result. In this paper, we will present the application of analytic hierarchical process method "AHP" to resolve the problem of game genre selection, then, we will discuss the results to see if the chosen method gives the right decision that will help game developers to choose easily the correct game genre.
\end{abstract}

\section{General Terms}

Video Game Genre Selection

\section{Keywords}

AHP, Multi-criteria Decision Making, Game genre

\section{INTRODUCTION}

Video games are often classified into genres, which purport to define games in terms of having a common style or set of properties or characteristics, like defined in terms of perspective, gameplay, interaction, objectives. The typical genres include: Strategy, Action, FPS, Role-Playing (RPG), Fighting, Racing, Sports, Simulation, Family, Child, and Adventure $[1,2]$.Table 1 shows a simplified overview of the six best known game genres.

Table 1. The Overview of various game genres

\begin{tabular}{|c|l|}
\hline $\begin{array}{c}\text { Action } \\
\text { games }\end{array}$ & $\begin{array}{l}\text { Games with a heavy emphasis on a series of } \\
\text { actions performed by the player in order to } \\
\text { meet a certain set of objectives. }\end{array}$ \\
\hline $\begin{array}{c}\text { Adventure } \\
\text { games }\end{array}$ & $\begin{array}{l}\text { Adventure games place the main emphasis on } \\
\text { the story. The objective is normally to gather } \\
\text { objects and solve codes and mysteries in order } \\
\text { to advance in the game. Players need to use } \\
\text { logical problem-solving skills. }\end{array}$ \\
\hline $\begin{array}{c}\text { Role- } \\
\text { playing } \\
\text { Games }\end{array}$ & $\begin{array}{l}\text { RPG games with an emphasis on the player's } \\
\text { character development and narrative } \\
\text { components. }\end{array}$ \\
\hline $\begin{array}{c}\text { Strategy } \\
\text { games }\end{array}$ & $\begin{array}{l}\text { Games characterized by players strategic } \\
\text { decisions and interventions to bring the desired } \\
\text { outcome }\end{array}$ \\
\hline $\begin{array}{c}\text { Simulator } \\
\text { games }\end{array}$ & $\begin{array}{l}\text { Games intending to recreate an experience of } \\
\text { areal word activity in the game world }\end{array}$ \\
\hline $\begin{array}{c}\text { Puzzle } \\
\text { games }\end{array}$ & $\begin{array}{l}\text { This type of game mainly involves solving } \\
\text { puzzles. These games do not usually have a } \\
\text { story element. They include mathematical and } \\
\text { timed problems. }\end{array}$ \\
\hline
\end{tabular}

However, current descriptors of video game genres are none standardized, undefined and embedded with multiple information [3]. Therefore, these problems can influence the outcome of the video games development process, and cause difficulties in choosing the right game genre that will meet the need envisaged by video game creators.

In this paper we will present the application of analytic hierarchical process "AHP" for video game genre selection via a web application, the selection will be done dynamically according to the parameters passed by the users, and AHP method will be fed by the values of statistical study about serious games done by our research team. An evaluation of how the chosen method proved successful along with an outlook on future research concludes this paper.

\section{LITERATURE RIVIEW}

Multi-Criteria Decision Making (MCDM) is the study of methods and procedures by which concerns about multiple conflicting criteria can be formally incorporated into the management planning process [4]. MCDM is a structured framework for analyzing decision problems characterized by complex multiple objectives [5]. The MCDM process typically defines objectives, chooses the criteria to measure the objectives, specifies alternatives, transforms the criterion scales into commensurable units, assigns weights to the criteria that reflect their relative importance, selects and applies a mathematical algorithm for ranking alternatives, and chooses an alternative $[6,7,8,9]$.The analytic hierarchy process "AHP" is a multi-criteria decision making method "MCDM", it's also a powerful tool that may be used to make decisions when multiple and conflicting objectives/criteria are present, and both qualitative and quantitative aspects of a decision need to be considered [10]. The AHP provides the objective mathematics to process the inescapably subjective and personal preferences of an individual or a group in making a decision [11].The AHP method has been studied extensively and used in almost all the applications related with multiple criteria decision making (MCDM) in the last decade, several papers in multi criteria decision have used this method, 150 articles investigating the AHP combined with general applications [12], 18 articles studying the AHP combined with finance simply [13].The AHP method was adopted in education, engineering, government, industry, management, manufacturing, personal, political, social, and sports [12]. 


\section{STATISTICAL STUDY OF VIDEO GAME GENRES}

In order to feed the system of multi-criteria decision making based on AHP method, we have decided to do a statistical study [14] concerning different online serious games since their genre, we have filtered the results according to three main criteria "age, field and properties" and for each main criterion there are sub criteria, for the age there are three intervals "3-10, $10-18$ and +18 ", for the field there are also four sub criterion "education, economy, health care and environment," and for the properties there are nine sub criteria which refer to properties related to video games "Speed, Skills based, Intelligence, Precision, Reflection, Decision, Funny, Knowledge and Chance", Table 2 contains all percentages according to the genre and criteria mentioned above. These percentages will be used by the AHP method, to make decisions in order to select the game genre according to the parameters given by the users. The decision will help both game designers and game developers to select the best choice that meets the result that responds to the need.

\section{APPLICATION OF AHP FOR GAME GENRE SELECTION}

Problem of game genre selection has been dealt with using a statistical study detailed above; the study has concerned several online serious games to extract criteria that will be used by the AHP method to classify game genres according to the parameters chosen by the users.

In this work, the AHP method is used to select the most suitable video game genre according to the parameters given by the users. In general, the AHP method consists of four main phases, including problem structuring, data collection, relative weight evaluation and problem solution establishment. The Fig 1 below explains the process flowed to do the game genre selection by using the AHP method.

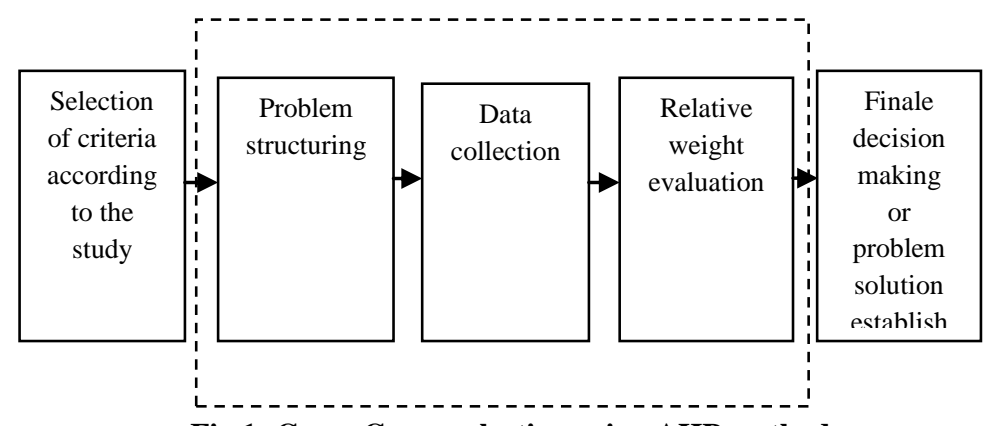

Fig 1: Game Genre selection using AHP method

\subsection{Problem structuring}

The problem structuring consists of decomposing a certain complex problem of decision making into a series of hierarchies where each level represents a smaller number of managed attributes. Among the rules to construct a good hierarchical structure for decision making, there are the clear definition of the decision problem and the determination of the main goal, the structure of the hierarchy from the top through the intermediate levels to the lowest levels. In Fig 2 the goal of the problem is located at level 0 . Level 1 houses the major criteria and the level 2 contains all the sub-criteria. Finally, the alternatives are located at the last level of the hierarchy. The game genre selection criteria and the alternatives detail in Fig 2.

\subsection{Data collection}

The second phase in AHP process consists of collecting data and its calculation. The decision maker assigns relative weight to pairs of attributes of a single hierarchy level, for all levels of the hierarchy, by using the most common scale of nine levels Table 3.

Table 3. The fundamental scale for pair-wise comparison

\begin{tabular}{|c|c|c|}
\hline $\begin{array}{l}\text { Intensity of } \\
\text { importance }\end{array}$ & Definition & Explanation \\
\hline 1 & $\begin{array}{c}\text { Equal } \\
\text { importance }\end{array}$ & $\begin{array}{l}\text { Two elements contribute } \\
\text { equal to the objective }\end{array}$ \\
\hline 3 & $\begin{array}{l}\text { Moderate } \\
\text { importance }\end{array}$ & $\begin{array}{l}\text { Experience and judgment } \\
\text { moderately favor one } \\
\text { element over another }\end{array}$ \\
\hline 5 & $\begin{array}{l}\text { Strong } \\
\text { importance }\end{array}$ & $\begin{array}{l}\text { Experience and judgment } \\
\text { strongly favor one } \\
\text { element over another }\end{array}$ \\
\hline 7 & $\begin{array}{l}\text { Very Strong } \\
\text { importance }\end{array}$ & $\begin{array}{l}\text { One element is favored } \\
\text { very strongly over } \\
\text { another its dominance is } \\
\text { demonstrated in practice }\end{array}$ \\
\hline 9 & $\begin{array}{l}\text { Extreme } \\
\text { importance }\end{array}$ & $\begin{array}{l}\text { The evidence favoring } \\
\text { one element over another } \\
\text { of the highest possible } \\
\text { order of affirmation }\end{array}$ \\
\hline & $\begin{array}{r}\text { of } 2,4,6 \text { a } \\
\text { interme }\end{array}$ & $\begin{array}{l}\text { a be used to express } \\
\text { alues. }\end{array}$ \\
\hline
\end{tabular}

The set of criteria is, composed of $n$ elements $C=\{C 1, ., C n\}$. The result of the evaluation matrix in which every element $\mathrm{a}_{\mathrm{i}, \mathrm{j}}$ $(I, j=1,2 \ldots ., n)$ is the quotient of the weights of the criteria.

$$
\mathrm{A}=\left[\begin{array}{ccc}
\mathrm{a} 1,1 & \cdots & \text { a } 1, \mathrm{n} \\
\vdots & \ddots & \vdots \\
\mathrm{a} n, 1 & \cdots & \text { a } n, \mathrm{n}
\end{array}\right]=\mathrm{a}_{11}=1, \mathrm{a}_{\mathrm{ij}}=1 / \mathrm{a}_{\mathrm{ji}}, \mathrm{a}_{\mathrm{ij}} \neq 0 .
$$

\subsection{Relative weight evaluation}

In this phase of AHP method the pair-wise matrix, by pairs, transfers into problems of own value determination in order to get the normalized and a single eigenvector, as well as the weight of all attribute on each hierarchy level.

\subsubsection{Problem resolution}

The problem resolution is the final phase of the AHP method and it involves the establishment of the so-called composite normalized vector. The determination of alternatives importance in the model comes next, within each criterion. The final step consists of synthesizing the total problem by carried out in the following way: the weight of each criterion is multiplied by the weight of the reviewed criterion, and these values are the summarized for each alternative separately. The result is the weight of the reviewed alternative within the model. The weight of the rest of the alternatives is calculated in the same way; finally, the final ranking of alternatives is determined.

\subsubsection{Consistency verification}

Saaty [1] recommended that the maximum eigenvalue, $\lambda_{\max }$ can be determined as:

$$
\lambda_{\max }=\sum_{j=1} \text { aij } \frac{W j}{W i}
$$


Where $\lambda_{\max }$ is the maximum eigenvalue of positive real values in judgment matrix, $w_{j}$ is the weight of the $j_{t h}$ factor, and $w_{i}$ is the weight of $i_{\text {th }}$ factor.

Eigenvector $\mathrm{X}$ can be determined as:

$$
(A-\lambda \max I) X=0
$$

Saaty [1] recommended using consistency index (CI) and consistency ratio (CR) to check for the consistency associated with the comparison matrix.

Saaty [1] demonstrated that for a consistent reciprocal matrix, the largest eigenvalue is equal to the number of comparisons, or $\lambda_{\max }=\mathrm{n}$. Then he gave a measure of consistency, called the consistency Index as a deviation or a degree of consistency using the following formula by using (3):

$$
\mathrm{CI}=\frac{(\lambda \max -\mathrm{n})}{\mathrm{n}-1}
$$

Knowing the Consistency Index, we can calculate the consistency ratio (CR) by using (3):

$$
\mathrm{CR}=\frac{\mathrm{CI}}{\mathrm{RI}}=\left[\frac{\lambda \max -\mathrm{n}}{\mathrm{n}-1}\right] / \mathrm{RI}(5)
$$

Where RI represents average consistency index over a number of random entries of some order reciprocal matrices presented in Table 4.

\section{Table 4.The Reference Values of RI Different Numbers}

\begin{tabular}{|c|c|}
\hline $\mathbf{N}$ & $\mathbf{R I}$ \\
\hline 2 & 0 \\
\hline 3 & 0.58 \\
\hline 4 & 0.90 \\
\hline 5 & 1.12 \\
\hline 6 & 1.24 \\
\hline 7 & 1.32 \\
\hline 8 & 1.41 \\
\hline 9 & 1.45 \\
\hline 10 & 1.49 \\
\hline
\end{tabular}

The ratio of coherence can be interpreted as the probability that random matrix is full. The overall coherence of appreciation is assessed using the consistency ratio (RC). According to Saaty[1], if the value of Consistency Ratio is smaller or equal to $10 \%$, the inconsistency is acceptable. Alternatively, if the Consistency Ratio is greater than $10 \%$, the subjective judgment should be revised.

\subsection{Application}

According to the theoretical part of this section we have implemented the hierarchical structure dedicated to game genre selection it's composed of four levels; Level contains the main goal or objective "selection of game genre".

Level 1 there are three criteria "age, filed and properties", level 2 there are three sets of sub-criteria related for each criterion of level 1 , in our case there are three sub-criteria related to age criterion, four sub-criteria related to field criterion and nine sub-criteria "Speed, Skills based, Intelligence, Precision, Reflection, Decision, Funny, Knowledge and Chance" related to properties, for the alternatives there are seven elements "RPG, RTS, Simulation, Platformer, Adventure, Puzzle and Flash" at the end of the structure Fig 3. After implementation of hierarchical structure we can calculate the pair-wise comparison matrix for all levels existing in hierarchical structure.

\subsubsection{Pair-wise comparison of level 1}

The Matrix of Pair-wise comparison of level 1 that concerns the three criteria "Age, Field, and Properties" is detailed in Table 5.

Table 5.First level attributes comparison

\begin{tabular}{|c|c|c|c|c|}
\hline Goal & Age & Field & Properties & Weight \\
\hline Age & 1 & 3 & $1 / 4$ & 0.23 \\
\hline Field & $1 / 3$ & 1 & $1 / 5$ & 0.10 \\
\hline Properties & 4 & 5 & 1 & 0.66 \\
\hline
\end{tabular}

As can be seen from the table, we have given preference value to each criterion. The preference values (1/3) of field criterion to age criterion means that the age criterion is moderately important then field criterion. Correspondingly the Properties criterion is strongly important than field and the properties criterion is also moderately important then the age criterion.

$$
\lambda_{\max }=3.08 ; \mathrm{CI}=0.04 ; \mathrm{CR}=0.04<0.1
$$

\subsubsection{Pair-wise comparison of sub level related to Age}

For the sub criteria related to age there are three ranges of age "3-10, $10-18,+18$ ", we decided to give all the elements the same value of priority "Equal importance", the pair-wise comparison matrix of sub level related to age is detailed in Table 6. For the calculation of global priorities it depends on the range of age given by the user.

\section{Table 6: Sub level age attributes comparison}

\begin{tabular}{|c|c|c|c|c|}
\hline & C1 & C2 & C3 & weight \\
\hline $\mathbf{3 - 1 0}(\mathbf{C 1})$ & 1 & 1 & 1 & 0.33 \\
\hline $\mathbf{1 0}-\mathbf{1 8}(\mathbf{C 2})$ & 1 & 1 & 1 & 0.33 \\
\hline$+\mathbf{1 8}(\mathbf{C 3})$ & 1 & 1 & 1 & 0.33 \\
\hline
\end{tabular}

$$
\lambda_{\max }=3.0 ; \mathrm{CI}=0.0 ; \mathrm{CR}=0.0<0.1
$$

\subsubsection{Pair-wise comparison of sub level related to Filed}

For the sub criteria related to field there are four fields "Education, Health care, Economy and Environment" we decided to give all the elements the same value of priority "Equal importance", the pair-wise comparison matrix of sub level related to the field is detailed in Table 7. For the calculation of global priorities its depend to the field chosen by the user.

Table 7: Sub level field attributes comparison

\begin{tabular}{|c|c|c|c|c|}
\hline & C1 & C2 & C3 & Weight \\
\hline Education(C1) & 1 & 1 & 1 & 0.25 \\
\hline Health care (C2) & 1 & 1 & 1 & 0.25 \\
\hline Economy (C3) & 1 & 1 & 1 & 0.25 \\
\hline Environment (C4) & 1 & 1 & 1 & 0.25 \\
\hline
\end{tabular}

$$
\lambda_{\max }=4.0 ; \mathrm{CI}=0.0 ; \mathrm{CR}=0.0<0.1
$$


4.4.4 Pair-wise comparison of sub level related to Priorities

For the sub criteria related to properties there are nine properties "Speed, Skills based, Intelligence, Precision, Reflection, Decision, Funny, Knowledge and Chance", we decided to give all the elements the same value of priority "Equal importance", the pair-wise comparison matrix of sub level related to properties is detailed in Table 8. For the calculation of global priorities it depends to the number of proprieties chosen by the user.

Table 8: A Sub level property attributes comparison

\begin{tabular}{|c|c|}
\hline & Local weight \\
\hline Speed & 0.111 \\
\hline Skills based & 0.111 \\
\hline Intelligence & 0.111 \\
\hline Precision & 0.111 \\
\hline Reflection & 0.111 \\
\hline Decision & 0.111 \\
\hline Funny & 0.111 \\
\hline Knowledge & 0.111 \\
\hline Chance & 0.111 \\
\hline
\end{tabular}

$$
\lambda \max =9.0 ; \mathrm{CI}=0.0 ; \mathrm{CR}=0.0<0.1
$$

\subsubsection{Pair-wise comparison of alternatives}

For the proposed hierarchical structure there are seven genres "RPG, RTS, Simulation, Platformer, Adventure, Puzzle and Flash", the Pair-wise comparison has to be calculated by the local and global weight for each sub criterion connected to each game genre the tables from 9 to 24 .

Table 9: Local weights of sub criterion $[3-10]$ years

\begin{tabular}{|c|c|}
\hline & Local weight \\
\hline RTS & 0.054 \\
\hline RPG & 0.030 \\
\hline Simulation & 0.019 \\
\hline Flash & 0.257 \\
\hline Platformer & 0.214 \\
\hline Puzzle & 0.214 \\
\hline Adventure & 0.209 \\
\hline
\end{tabular}

$$
\lambda_{\max }=7.86 ; \mathrm{CI}=0.14 ; \mathrm{CR}=0.1<=0.1
$$

Table 10: Local weights of sub criterion [10 - 18] years

\begin{tabular}{|c|c|}
\hline & Local weight \\
\hline RTS & 0.261 \\
\hline RPG & 0.261 \\
\hline Simulation & 0.261 \\
\hline Flash & 0.040 \\
\hline Platformer & 0.092 \\
\hline Puzzle & 0.040 \\
\hline Adventure & 0.040 \\
\hline
\end{tabular}

$$
\lambda_{\max }=7.11 ; \mathrm{CI}=0.01 ; \mathrm{CR}=0.01<0.1
$$

Table 11: Local weights of sub criterion $[+18]$ years

\begin{tabular}{|c|c|}
\hline & Local weight \\
\hline RTS & 0.139 \\
\hline RPG & 0.139 \\
\hline Simulation & 0.424 \\
\hline Flash & 0.074 \\
\hline Platformer & 0.074 \\
\hline Puzzle & 0.074 \\
\hline Adventure & 0.074 \\
\hline
\end{tabular}

$$
\lambda_{\max }=7.03 ; \mathrm{CI}=0.006 ; \mathrm{CR}=0.004<0.1
$$

Table 12: Local weights of sub criterion Education

\begin{tabular}{|c|c|}
\hline & Local weight \\
\hline RTS & 0.022 \\
\hline RPG & 0.054 \\
\hline Simulation & 0.029 \\
\hline Flash & 0.174 \\
\hline Platformer & 0.174 \\
\hline Puzzle & 0.174 \\
\hline Adventure & 0.371 \\
\hline
\end{tabular}

$$
\lambda_{\max }=7.31 ; \mathrm{CI}=0.05 ; \mathrm{CR}=0.03<0.1
$$

Table 13: Local weights of sub criterion Health care

\begin{tabular}{|c|c|}
\hline & Local weight \\
\hline RTS & 0.088 \\
\hline RPG & 0.100 \\
\hline Simulation & 0.170 \\
\hline Flash & 0.088 \\
\hline Platformer & 0.290 \\
\hline Puzzle & 0.170 \\
\hline Adventure & 0.088 \\
\hline
\end{tabular}

$$
\lambda \max =7.14 ; \mathrm{CI}=0.02 ; \mathrm{CR}=0.01<0.1
$$

Table 14: Local weights of sub criterion Economy

\begin{tabular}{|c|c|}
\hline & Local weight \\
\hline RTS & 0.419 \\
\hline RPG & 0.227 \\
\hline Simulation & 0.162 \\
\hline Flash & 0.047 \\
\hline Platformer & 0.047 \\
\hline Puzzle & 0.047 \\
\hline Adventure & 0.047 \\
\hline
\end{tabular}

$$
\lambda_{\max }=7.11 ; \mathrm{CI}=0.01 ; \mathrm{CR}=0.01<0.1
$$

Table 15: Local weights of sub criterion Environment

\begin{tabular}{|c|c|}
\hline Table 15: Local weights of sub criterion Environment \\
\hline & Local weight \\
\hline RTS & 0.339 \\
\hline RPG & 0.137 \\
\hline Simulation & 0.222 \\
\hline Flash & 0.075 \\
\hline Platformer & 0.075 \\
\hline Puzzle & 0.075 \\
\hline Adventure & 0.339 \\
\hline
\end{tabular}

$$
\lambda_{\max }=7.02 ; \mathrm{CI}=0.004 ; \mathrm{CR}=0.003<0.1
$$

Table 16: Local weights of sub criterion Speed

\begin{tabular}{|c|c|}
\hline & Local weight \\
\hline RTS & 0.060 \\
\hline RPG & 0.060 \\
\hline Simulation & 0.140 \\
\hline Flash & 0.191 \\
\hline Platformer & 0.457 \\
\hline Puzzle & 0.027 \\
\hline Adventure & 0.062 \\
\hline
\end{tabular}

$$
\lambda_{\max }=7.21 ; \mathrm{CI}=0.03 ; \mathrm{CR}=0.02<0.1
$$


Table 17: Local weights of sub criterion properties Skills based

\begin{tabular}{|c|c|}
\hline & Local weight \\
\hline RTS & 0.104 \\
\hline RPG & 0.328 \\
\hline Simulation & 0.074 \\
\hline Flash & 0.033 \\
\hline Platformer & 0.104 \\
\hline Puzzle & 0.020 \\
\hline Adventure & 0.332 \\
\hline
\end{tabular}

$$
\lambda_{\max }=7.52 ; \mathrm{CI}=0.08 ; \mathrm{CR}=0.06<0.1
$$

Table 18: Local weights of sub criterion Intelligence

\begin{tabular}{|c|c|}
\hline & Local weight \\
\hline RTS & 0.293 \\
\hline RPG & 0.043 \\
\hline Simulation & 0.043 \\
\hline Flash & 0.177 \\
\hline Platformer & 0.043 \\
\hline Puzzle & 0.332 \\
\hline Adventure & 0.067 \\
\hline
\end{tabular}

$$
\lambda_{\max }=7.21 ; \mathrm{CI}=0.03 ; \mathrm{CR}=0.02<0.1
$$

Table 19: Local weights of sub criterion Reflection

\begin{tabular}{|c|c|}
\hline & Local weight \\
\hline RTS & 0.042 \\
\hline RPG & 0.108 \\
\hline Simulation & 0.064 \\
\hline Flash & 0.283 \\
\hline Platformer & 0.108 \\
\hline Puzzle & 0.283 \\
\hline Adventure & 0.108 \\
\hline
\end{tabular}

$$
\lambda_{\max }=7.06 ; \mathrm{CI}=0.01 ; \mathrm{CR}=0.007<0.1
$$

Table 20: Local weights of sub criterion Precision

\begin{tabular}{|c|c|}
\hline & Local weight \\
\hline RTS & 0.033 \\
\hline RPG & 0.110 \\
\hline Simulation & 0.034 \\
\hline Flash & 0.302 \\
\hline Platformer & 0.077 \\
\hline Puzzle & 0.409 \\
\hline Adventure & 0.032 \\
\hline
\end{tabular}

$$
\lambda_{\max }=7.25 ; \mathrm{CI}=0.04 ; \mathrm{CR}=0.02<0.1
$$

Table 21: Local weights of sub criterion Decision

\begin{tabular}{|c|c|}
\hline & Local weight \\
\hline RTS & 0.317 \\
\hline RPG & 0.197 \\
\hline Simulation & 0.317 \\
\hline Flash & 0.086 \\
\hline Platformer & 0.026 \\
\hline Puzzle & 0.026 \\
\hline Adventure & 0.026 \\
\hline
\end{tabular}

$$
\lambda_{\max }=7.47 ; \mathrm{CI}=0.07 ; \mathrm{CR}=0.05<0.1
$$

Table 22: Local weights of sub criterion Funny

\begin{tabular}{|c|c|}
\hline & Local weight \\
\hline RTS & 0.042 \\
\hline RPG & 0.066 \\
\hline Simulation & 0.042 \\
\hline Flash & 0.157 \\
\hline Platformer & 0.237 \\
\hline Puzzle & 0.103 \\
\hline Adventure & 0.350 \\
\hline
\end{tabular}

$$
\lambda_{\max }=7.14 ; \mathrm{CI}=0.02 ; \mathrm{CR}=0.01<0.1
$$

Table 23: Local weights of sub criterion Knowledge

\begin{tabular}{|c|c|}
\hline & Local weight \\
\hline RTS & 0.244 \\
\hline RPG & 0.244 \\
\hline Simulation & 0.244 \\
\hline Flash & 0.065 \\
\hline Platformer & 0.102 \\
\hline Puzzle & 0.032 \\
\hline Adventure & 0.065 \\
\hline
\end{tabular}

$$
\lambda_{\max }=7.12 ; \mathrm{CI}=0.02 ; \mathrm{CR}=0.01<0.1
$$

Table 24: Local weights of sub criterion Chance

\begin{tabular}{|c|c|}
\hline & Local weight \\
\hline RTS & 0.081 \\
\hline RPG & 0.437 \\
\hline Simulation & 0.153 \\
\hline Flash & 0.081 \\
\hline Platformer & 0.081 \\
\hline Puzzle & 0.081 \\
\hline Adventure & 0.081 \\
\hline
\end{tabular}

$$
\lambda_{\max }=7.02 ; \mathrm{CI}=0.003 ; \mathrm{CR}=0.002<0.1
$$

For the global weights related to each alternative are calculated dynamically according to the parameters given by the users via the web application.

\section{RESULTS}

As said before the users will use a web application that implements the AHP algorithm, and according to the parameters given by them the application will rank the game genres by summing the global weight of each criterion. For example if the user chooses these parameters "age $=15$ that belong to the interval $(10-18)$, filed = Education and the properties checked is knowledge, Decision and Intelligence" see Fig 4.

Table 24: Total weighted score of games genres

\begin{tabular}{|c|c|c|c|c|c|c|c|}
\hline & C1 & C2 & C3 & C4 & C5 & C6 & C7 \\
\hline$[\mathbf{1 0}$-18] & 0.060 & 0.060 & 0.060 & 0.009 & 0.021 & 0.09 & 0.09 \\
\hline Education & 0.002 & 0.006 & 0.003 & 0.018 & 0.018 & 0.018 & 0.038 \\
\hline knowledge & 0.162 & 0.162 & 0.162 & 0.043 & 0.068 & 0.021 & 0.043 \\
\hline Decision & 0.211 & 0.131 & 0.211 & 0.057 & 0.017 & 0.017 & 0.017 \\
\hline Intelligence & 0.195 & 0.029 & 0.028 & 0.118 & 0.029 & 0.221 & 0.045 \\
\hline Total score & 0.63 & 0.39 & 0.47 & 0.25 & 0.15 & 0.29 & 0.15 \\
\hline
\end{tabular}

"RTS $=\mathrm{C} 1$, RPG $=\mathrm{C} 2$, Simulation $=\mathrm{C} 3$, Flash $=\mathrm{C} 4$, Platformer $=\mathrm{C} 5$, Puzzle $=\mathrm{C} 6$ and Adventure $=\mathrm{C} 7$ " .

According to the results (Table 24) found in the game genre selection, RTS appears to be the best choice of all seven game genres based on its highest total score. The results found through the AHP implementation were reliable as the evaluation criteria matched the case game genre selection, 
pair-wise comparison were made via informed judgments and were consistent, and mathematical calculations were completed and validated thought the algorithm implemented on the web application.

\section{CONCLUSION AND PERSPECTIVES}

This paper identifies the application of the AHP approach that helps game designers, game developers and other users to rank the game genres according to the parameters given by them. The role of game genre selection has become more than ever imperative for game designers to create their own video games. Among the perspectives considered there is the development of a game generator that will be oriented by the web application based on AHP approach, the game generator will be dedicated to the non-experts "Instructors and Trainers" that allows the generation of different serious games without the interaction of game programmers or artistic team.

\section{ACKNOWLEDGMENTS}

We gratefully acknowledge the support of the students and all other participants.

\section{REFERENCES}

[1] Fullerton, T., Swain, C., and Hoffman, S. 2004. Game Design Workshop: Designing, Prototyping, and Play testing Games. CMP Boocks, February.

[2] ESA. 2005. Entertainment Software Association / NPD Group 2005 Sales and Genre Data. http://www.theesa.com/facts/salesgenredata.php, viewed March 20, 2007.

[3] Lee, J. H., Karlova, N., Clarke, R. I., Thornton, K., \&Perti, A. (2014). Facet Analysis of Video Game Genres. In iConference 2014 Proceedings (p. 125-139).

[4] Chen, M. F., Tzeng, G. H., Ding, CG., Combining Fuzzy AHP with MDS In Identifying The Preference Similarity of Alternatives. Applied Soft Computing, vol1 pp. 110117,2008 .
[5] Nijkamp, P., Rietveld, P., Voogd, H., 1990. Multicriteria Evaluation in Physical Planning. North-Holland, Amsterdam.

[6] Howard, A.F., 1991. A critical look at multiple criteria decision-making techniques with reference to forestry applications. Canadian Journal of Forest Research 21, 1649-1659.

[7] Keeney, R.L., 1992. Value-Focused Thinking: A Path to Creative Decision Analysis. Harvard University Press, Cambridge.

[8] Hajkowicz, S.A., Prato, T., 1998. Multiple objective decision analysis of farming systems in Goodwater Creek Watershed, Missouri. Research Report No. 24, Centre for Agriculture, Resources and Environmental Systems, Columbia, Missouri.

[9] Massam, B.H., 1988. Multi-criteria decision-making techniques in planning. Progress in Planning 30, 1-84.

[10] Saaty, T.L. The Analytic Hierarchy Process. New York, New York: McGraw-Hill International, 1980.

[11] Schmoldt, Daniel L., et al. The Analytic Heirarchy Process in Natural Resource and Environmental Decision Making. Dordrecht, the Netherlands: Kluwer Academic Publishers, p 15, 2001.

[12] Vaidya, O.S., Kumar, S., 2006. Analytic hierarchy process: An overview of applications. European Journal of Operational Research 169 (1), 1-29.

[13] Steuer, R.E., Na, P., 2003. Multiple criteria decision making combined with finance: A categorized bibliographic study European Journal of Operational Research 150 (3), 496-515.

[14] Sglab, Video games statistical study. Internet: www.sglab.ma/list [May.15, 2014].
Level 1

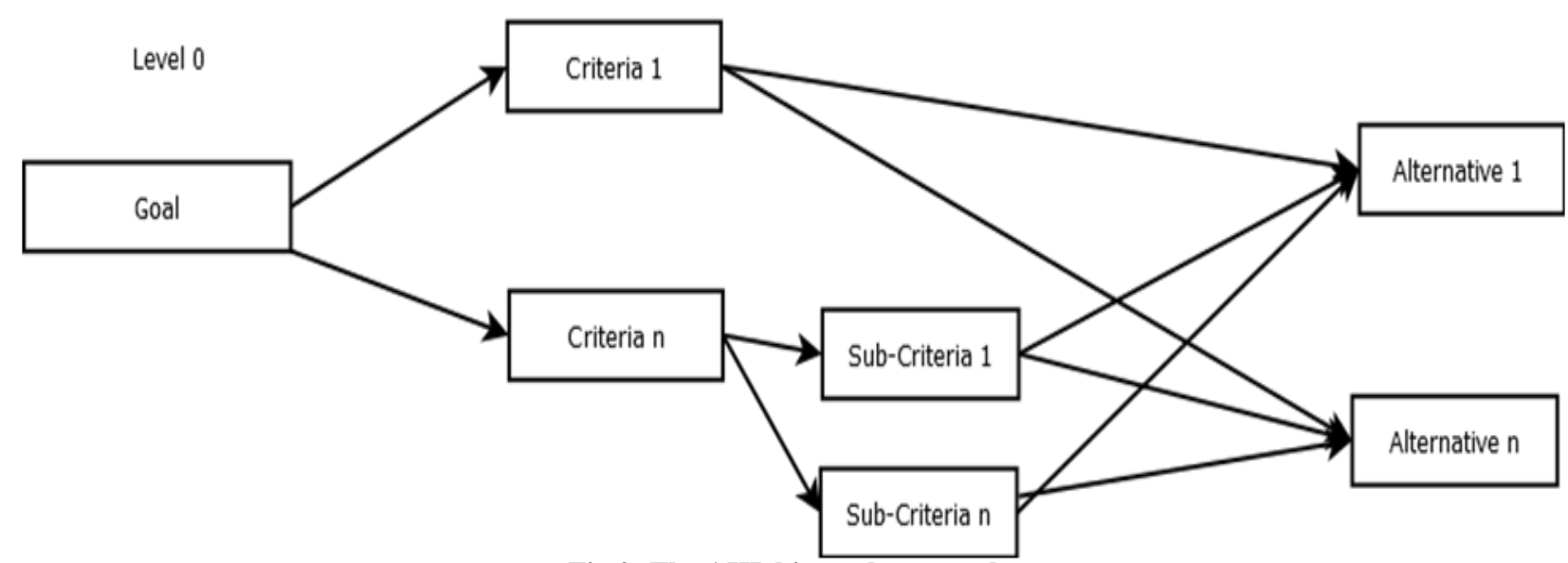

Fig 2: The AHP hierarchy example 


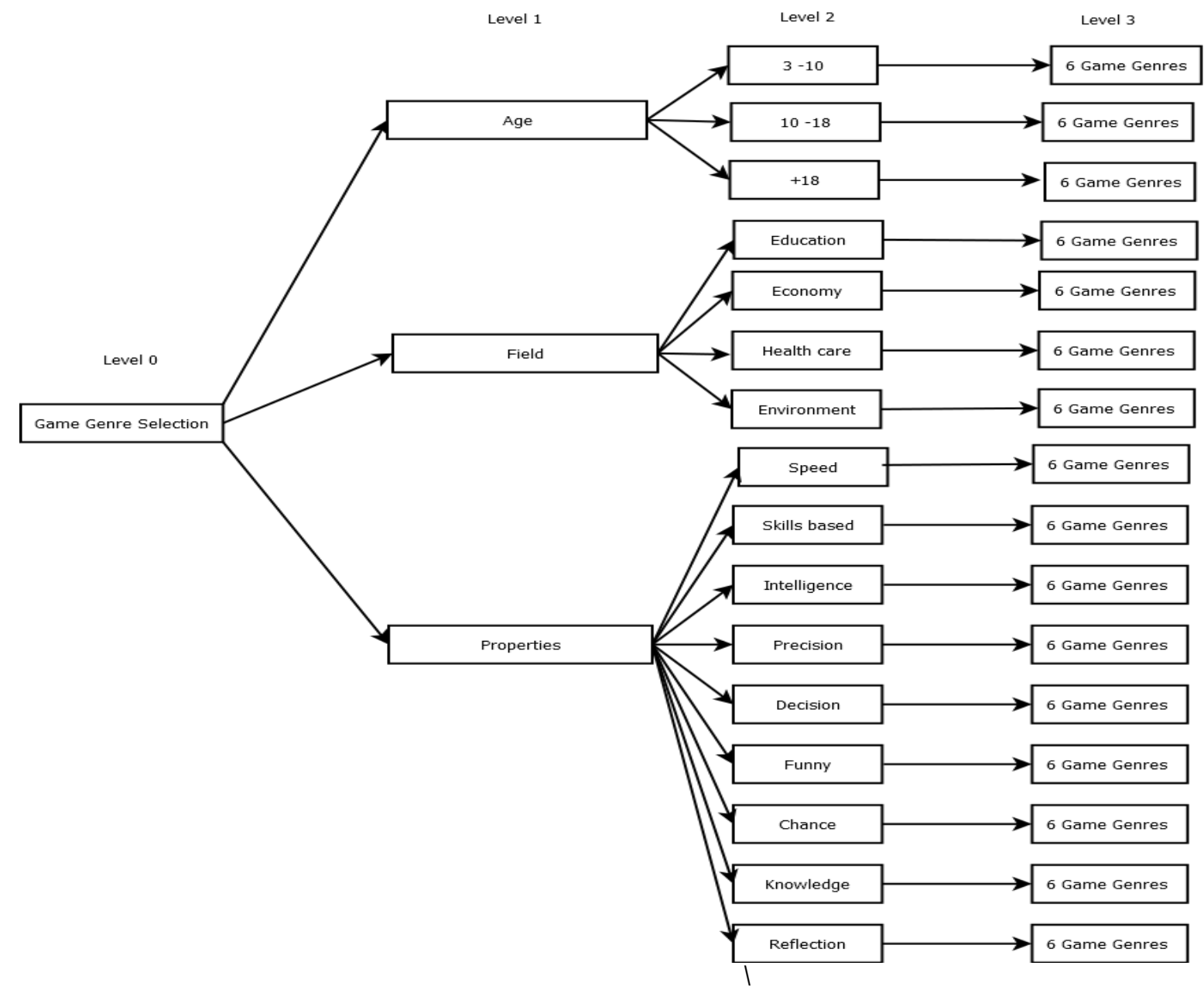

6 Game Genres

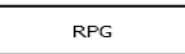

Fig 3: The AHP hierarchy for game genre selection

\section{Game generes selection}

Name: Gam
Age : 15
speed $\square$
skills based $\square$
Reflection $\square$
Knowledge $\square$

Name : Game1

Age : 15

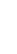

Reflection $\square$
Knowledge $\square$

Simulation Score : 0.47

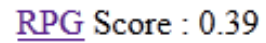

Puzzle Score : 0.29

Flash Score : 0.25

Adventure Score : 0.15

Platformer Score : 0.15

\section{Making Decision}

Fig 4: The web application developed by our research team for game genre selection based on The AHP method 
Table 2. Statistical study on serious games according to the genre

\begin{tabular}{|c|c|c|c|c|c|c|c|c|}
\hline & & RTS & RPG & Simulation & Flash & Platformer & Puzzle & Adventure \\
\hline \multirow{3}{*}{ Age } & $3-10$ & $40 \%$ & $28,57 \%$ & $7,14 \%$ & $92,31 \%$ & $80 \%$ & $81,82 \%$ & $100 \%$ \\
\hline & $10-18$ & $50 \%$ & $57,14 \%$ & $50 \%$ & $3,85 \%$ & $20 \%$ & $9,09 \%$ & $0 \%$ \\
\hline & +18 & $10^{\prime \prime}$ & $14,29 \%$ & $42,86 \%$ & $3,85 \%$ & $0 \%$ & $9,09 \%$ & $0 \%$ \\
\hline \multirow{4}{*}{ Field } & Economy & $60 \%$ & $42,86 \%$ & $35,71 \%$ & $3,85 \%$ & $0 \%$ & $0 \%$ & $0 \%$ \\
\hline & Education & $10 \%$ & $42,86 \%$ & $28,57 \%$ & $88,46 \%$ & $80 \%$ & $81,82 \%$ & $100 \%$ \\
\hline & Military & $0 \%$ & $0 \%$ & $14,29 \%$ & $3,85 \%$ & $20 \%$ & $18,18 \%$ & $0 \%$ \\
\hline & Environment & $30 \%$ & $14,29 \%$ & $21,43 \%$ & $3,85 \%$ & $0 \%$ & $0 \%$ & $0 \%$ \\
\hline \multirow{9}{*}{ Properties } & Speed & $20 \%$ & $28,00 \%$ & $42 \%$ & $50 \%$ & $80 \%$ & $0 \%$ & $25 \%$ \\
\hline & Skills based & $60 \%$ & $100 \%$ & $50 \%$ & $23 \%$ & $60 \%$ & $0 \%$ & $100 \%$ \\
\hline & Intelligence & $100 \%$ & $42 \%$ & $42 \%$ & $88 \%$ & $40 \%$ & $100 \%$ & $50 \%$ \\
\hline & Precision & $0 \%$ & $28 \%$ & $14 \%$ & $42 \%$ & $20 \%$ & $45,00 \%$ & $25 \%$ \\
\hline & Reflection & $20 \%$ & $57 \%$ & $28 \%$ & $96 \%$ & $40 \%$ & $100 \%$ & $25 \%$ \\
\hline & Decision & $100 \%$ & $85 \%$ & $100 \%$ & $42 \%$ & $0 \%$ & $0 \%$ & $0 \%$ \\
\hline & Funny & $0 \%$ & $14,00 \%$ & $0 \%$ & $38 \%$ & $40 \%$ & $27 \%$ & $50 \%$ \\
\hline & Knowledge & $100 \%$ & $100 \%$ & $100 \%$ & $76 \%$ & $80 \%$ & $54 \%$ & $75 \%$ \\
\hline & Chance & $0 \%$ & $42 \%$ & $14 \%$ & $3 \%$ & $0 \%$ & $0 \%$ & $0 \%$ \\
\hline
\end{tabular}

